\title{
Prognostic Impact of Carcinoembryonic Antigen Levels in Rectal Cancer Patients Who Had Received Neoadjuvant Chemoradiotherapy
}

\author{
Jung Il Joo, Sang Woo Lim, Bo Young Oh \\ Department of Surgery, Hallym University Sacred Heart Hospital, Hallym University College of Medicine, Anyang, Korea
}

Purpose: Carcinoembryonic antigen (CEA) is a useful marker for rectal cancer. The aim of this study was to investigate the prognostic impact of CEA level according to neoadjuvant chemoradiotherapy (nCRT) in rectal cancer patients who underwent radical surgery.

Methods: A total of 245 patients with rectal cancer who underwent radical surgery were retrospectively evaluated. Serum CEA level was measured preoperatively and postoperatively. We compared survival outcomes based on CEA level before and after surgery according to nCRT.

Results: Of the 245 patients, elevation of CEA level was observed preoperatively in 79 and postoperatively in 30, respectively. Eighty-seven (35.5\%) patients received nCRT, and elevated CEA level was a significant prognostic factor both before and after surgery. In patients who had not received nCRT, an elevated CEA level was a significant prognostic factor before surgery but was not significant after surgery. In a multivariate analysis for prognostic factors, elevation of preoperative CEA level was an independent prognostic factor of disease-free survival (DFS) regardless of nCRT. Postoperative CEA level was an independent prognostic factor of DFS in patients who had received nCRT but was not a factor in patients who had not received nCRT.

Conclusion: Serum CEA level was an independent prognostic factor both preoperatively and postoperatively in rectal cancer patients who had received nCRT.

Keywords: Carcinoembryonic antigen; Rectal neoplasms; Neoadjuvant therapy; Prognostic factors

\section{INTRODUCTION}

Colorectal cancer (CRC) is the third most frequently diagnosed malignancy and one of the leading causes of cancer-related mortality worldwide [1]. Rectal cancer accounts for approximately $30 \%$ of CRC and is associated with worse clinical outcomes $[2,3]$. The standard treatment of locally advanced rectal cancer is neo-

Received: Aug 5, 2020 - Revised: Nov 27, 2020 - Accepted: Nov 27, 2020 Correspondence to: Bo Young Oh, M.D.

Department of Surgery, Hallym University Sacred Heart Hospital, 22 Gwanpyeong-ro 170beon-gil, Dongan-gu, Anyang 14068, Korea Tel: +82-31-380-1614, Fax: +82-31-380-1619

E-mail:byoh@hallym.or.kr

ORCID: https://orcid.org/0000-0002-1255-0961

(C) 2021 The Korean Society of Coloproctology

This is an open-access article distributed under the terms of the Creative Commons Attribution NonCommercial License (https://creativecommons.org/licenses/by-nc/4.0) which permits unrestricted noncommercial use, distribution, and reproduction in any medium, provided the original work is properly cited. adjuvant chemoradiotherapy ( $\mathrm{nCRT}$ ) followed by total mesorectal excision to improve resectability, anal sphincter preservation, and local control. Selecting optimal treatments for individuals remains challenging for clinicians due to lack of effective markers [4]. In recent years, several markers have played an increasingly vital role in detection and management of CRC [5].

Carcinoembryonic antigen (CEA) is one of the most common and convenient indexes in patients with CRC. It has been used for diagnosing cancer, evaluating response to therapy, prognostic prediction, or detecting recurrence [6-9]. Although CEA is not a disease-specific marker, change from preoperative to postoperative CEA level has been suggested as an indicator of a higher recurrence rate. Many studies have investigated the role of CEA as a prognostic factor in CRC $[10,11]$. In earlier reports, elevated serum CEA level has been shown to have an adverse effect on prognosis of CRC $[12,13]$, whereas other studies have reported no relationship between serum CEA and oncologic outcomes $[14,15]$. 
However, a few studies have focused on rectal cancer and described the prognostic effect of CEA according to nCRT.

In this study, we investigated the prognostic impact of CEA level according to $\mathrm{nCRT}$ in rectal cancer patients who underwent radical surgery.

\section{METHODS}

The present study is based on the colorectal database of Hallym University Sacred Heart Hospital in Anyang, Korea. A total of 245 records of patients with rectal cancer who underwent radical surgery from January 2007 and December 2017 was retrospectively reviewed. All had histologically confirmed adenocarcinoma of the rectum. Patients were excluded if they had no data for preoperative or postoperative CEA, local excision, palliative surgery, synchronous malignancies, recurrent or metastatic disease, or hereditary cancer. This study was approved by Institutional Review Board of Hallym University Sacred Heart Hospital (No. 2020-07027). The requirement for informed consent was waived because of the retrospective nature of the study.

Patients with locally advanced rectal cancer were treated with $\mathrm{nCRT}$ that consisted of radiotherapy at a total dose of $50.4 \mathrm{~Gy}$ and concomitant chemotherapy based on either intravenous 5-fluorouracil or oral capecitabine. All had radical surgery between 6 and 10 weeks after completing nCRT. In contrast, patients with early rectal cancer immediately underwent radical surgery without nCRT. Intravenous 5-fluorouracil or oral capecitabine-based adjuvant chemotherapy was considered for either clinically or pathologically confirmed patients with locally advanced rectal cancer.

Postoperative surveillance was performed every 3 months for the first 2 years after surgery and then every 6 months for up to 5 years. Most patients were evaluated with a physical examination, serum

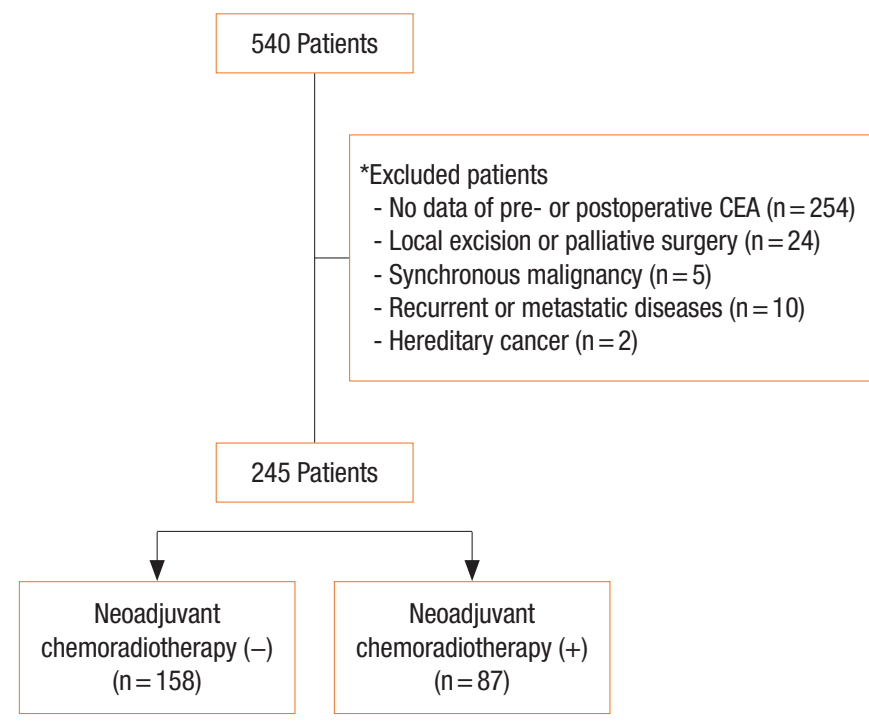

Fig. 1. Flowchart of patient selection.
Table 1. Patient characteristics

\begin{tabular}{|c|c|c|c|}
\hline Variable & $\begin{array}{l}\text { nCRT (-) } \\
(n=158)\end{array}$ & $\begin{array}{c}\mathrm{nCRT}(+) \\
(\mathrm{n}=87)\end{array}$ & P-value \\
\hline Age (yr) & & & 0.227 \\
\hline$<65$ & $69(43.7)$ & $45(51.7)$ & \\
\hline$\geq 65$ & 89 (56.3) & $42(48.3)$ & \\
\hline Sex & & & 0.021 \\
\hline Male & $85(53.8)$ & $60(69.0)$ & \\
\hline Female & 73 (46.2) & $27(31.0)$ & \\
\hline Preoperative CEA (ng/mL) & & & 0.002 \\
\hline$\leq 5$ & $96(60.8)$ & $70(80.5)$ & \\
\hline$>5$ & $62(39.2)$ & $17(19.5)$ & \\
\hline Postoperative CEA & & & 0.501 \\
\hline$\leq 5$ & $137(86.7)$ & 78 (89.7) & \\
\hline$>5$ & $21(13.3)$ & 9 (10.3) & \\
\hline Clinical stage & & & $<0.001$ \\
\hline I & $37(23.4)$ & $1(1.1)$ & \\
\hline$\|$ & $87(55.1)$ & $14(16.1)$ & \\
\hline III & $34(21.5)$ & $72(82.8)$ & \\
\hline Cancer obstruction & & & 0.137 \\
\hline Yes & $23(14.6)$ & $7(8.0)$ & \\
\hline No & $135(85.4)$ & $80(92.0)$ & \\
\hline Cancer perforation & & & 0.135 \\
\hline Yes & $4(2.5)$ & $0(0)$ & \\
\hline No & $154(97.5)$ & $87(100)$ & \\
\hline Approach of operation & & & 0.119 \\
\hline Minimally invasive surgery & $147(93.0)$ & $85(97.7)$ & \\
\hline Open & $11(7.0)$ & $2(2.3)$ & \\
\hline $\mathrm{p}$ (or yp)Stage & & & 0.659 \\
\hline 0 & $1(0.6)$ & $2(2.3)$ & \\
\hline । & 43 (27.2) & $26(29.9)$ & \\
\hline$\|$ & $54(34.2)$ & $27(31.0)$ & \\
\hline III & $60(38.0)$ & $32(36.8)$ & \\
\hline \multicolumn{4}{|l|}{ Cell type } \\
\hline WD/MD & $146(92.4)$ & 80 (92.0) & \\
\hline PD/MUC/SRC & $12(7.6)$ & $7(8.0)$ & \\
\hline Lymphatic invasion & & & 0.006 \\
\hline Yes & 51 (32.3) & $14(16.1)$ & \\
\hline No & $107(67.7)$ & 73 (83.9) & \\
\hline Vascular invasion & & & 0.134 \\
\hline Yes & $32(20.3)$ & $11(12.6)$ & \\
\hline No & $126(79.7)$ & 76 (87.4) & \\
\hline Perineural invasion & & & 0.126 \\
\hline Yes & 21 (13.3) & $6(6.9)$ & \\
\hline No & $137(86.7)$ & 81 (93.1) & \\
\hline Adjuvant treatment & & & $<0.001$ \\
\hline Yes & 77 (48.7) & 66 (75.9) & \\
\hline No & $81(51.3)$ & $21(24.1)$ & \\
\hline
\end{tabular}

Values are presented as number (\%).

nCRT, neoadjuvant chemoradiotherapy; CEA, carcinoembryonic antigen; $p$ (or yp) Stage, pathologic stage after surgical resection in patients who received preoperative treatment; WD, well differentiated; MD, moderately differentiated; PD, poorly differentiated; MUC, mucinous carcinoma; SRC, signet ring cell carcinoma. 
CEA level, and chest X-ray at each visit. Abdominopelvic and chest computed tomographies were performed every 6 months. Colonoscopy was performed after the first year and then biennially.

Serum CEA level was measured preoperatively and postoperatively (within 3 months after surgery and before starting adjuvant treatments). The interval between CEA measurement and surgery were reviewed preoperatively (median, 4 days; interquartile range [IQR], 6 days) and postoperatively (median, 7 days; IQR, 2 days). The normal range of serum CEA level was defined as less than or equal to $5 \mathrm{ng} / \mathrm{mL}$. The primary endpoint of this study was disease-free survival (DFS) based on CEA level according to nCRT.

Statistical analyses were performed using IBM SPSS Statistics for Windows (version 20.0; IBM Corp., Armonk, NY, USA). Survival rates were analyzed using the Kaplan-Meier method and the logrank test. Multivariate analyses for prognostic factors were performed using a Cox proportional hazard model. Variables that were significant in univariate analysis were entered into the multivariate model. The P-values were derived from two-tailed tests, and $\mathrm{P} \leq 0.05$ was considered statistically significant.

\section{RESULTS}

A total of 245 patients with rectal cancer was included in this study (Fig. 1). The clinicopathological features of the patients are described in Table 1. The patients included 145 males (59.2\%) and 100 females (40.8\%) with a median age of 66.0 years (range, $28-90$ years). Of these, 87 (35.5\%) received nCRT before surgery. Of the 245 patients, increased CEA level was observed preoperatively in $79(32.2 \%)$ and postoperatively in $30(12.2 \%)$. The median value for preoperative CEA level was $3.38 \mathrm{ng} / \mathrm{mL}$ (range, $0.01-383.0 \mathrm{ng} / \mathrm{mL}$ ) and postoperative CEA was $2.0 \mathrm{ng} / \mathrm{mL}$ (range, $0.1-666.1 \mathrm{ng} / \mathrm{mL}$ ).

To identify the impact of CEA on oncologic outcomes, we analyzed DFS according to CEA before and after surgery. The median follow-up duration was 47.3 months (range, $0.6-120.2$ months).
The 5-year DFS rates were significantly lower in patients with elevation of preoperative CEA level compared with patients with normal CEA level $(62.7 \%$ vs. $84.9 \%, \mathrm{P}<0.001)$ (Fig. 2 A). However, there was no significant difference in 5-year DFS rates according to postoperative CEA levels ( $75.1 \%$ vs. $78.6 \%, \mathrm{P}=0.424)$ (Fig. 2B).

To evaluate the prognostic value of CEA according to nCRT, we analyzed DFS according to CEA before and after surgery in each group. In patients who had not received nCRT, elevated CEA level was a significant prognostic factor before surgery but was not significant after surgery $(\mathrm{P}=0.013$ and $\mathrm{P}=0.710$, respectively) (Fig. $3 A)$. In patients who had received nCRT, elevated CEA level was a significant prognostic factor both before and after surgery $(\mathrm{P}=$ 0.002 and $\mathrm{P}=0.024$, respectively) (Fig. 3B). We performed additional analysis for DFS in each stage and confirmed that the results were similar to those of all patients (Supplementary Figs. 1-3).

In addition, we further analyzed DFS according to change in CEA level before and after surgery in patients who had received nCRT. The patients were divided into 3 groups according to the CEA levels as follows: group 1 (preoperative, $\leq 5 \mathrm{ng} / \mathrm{mL}$ and postoperative, $\leq 5 \mathrm{ng} / \mathrm{mL}$ ); group 2 (preoperative, $>5 \mathrm{ng} / \mathrm{mL}$ and postoperative, $\leq 5 \mathrm{ng} / \mathrm{mL}$ ); and group 3 (preoperative, $>5 \mathrm{ng} / \mathrm{mL}$ and postoperative, $>5 \mathrm{ng} / \mathrm{mL}$ ). As shown in Fig. 4 , the DFS was significantly worse in group 3 than in group 1 and group $2(\mathrm{P}=0.008)$.

Cox proportional hazard modeling was performed to identify whether CEA levels before and after surgery, according to nCRT, were an independent prognostic factor for survival outcomes in rectal cancer. In patients who had not received nCRT, elevation of preoperative CEA level was an independent prognostic factor of DFS ( $\mathrm{P}=0.049$; hazard ratio [HR], 2.017; 95\% confidence interval [CI], 1.002-4.058), but postoperative CEA level was not. In patients who had received nCRT, elevation of both preoperative and postoperative CEA level was an independent prognostic factor of DFS ( $\mathrm{P}=0.017$; HR, 5.443; 95\% CI, 1.356-21.848; and $\mathrm{P}=0.036$; HR, 3.983; 95\% CI, 1.093-14.515, respectively) (Table 2).
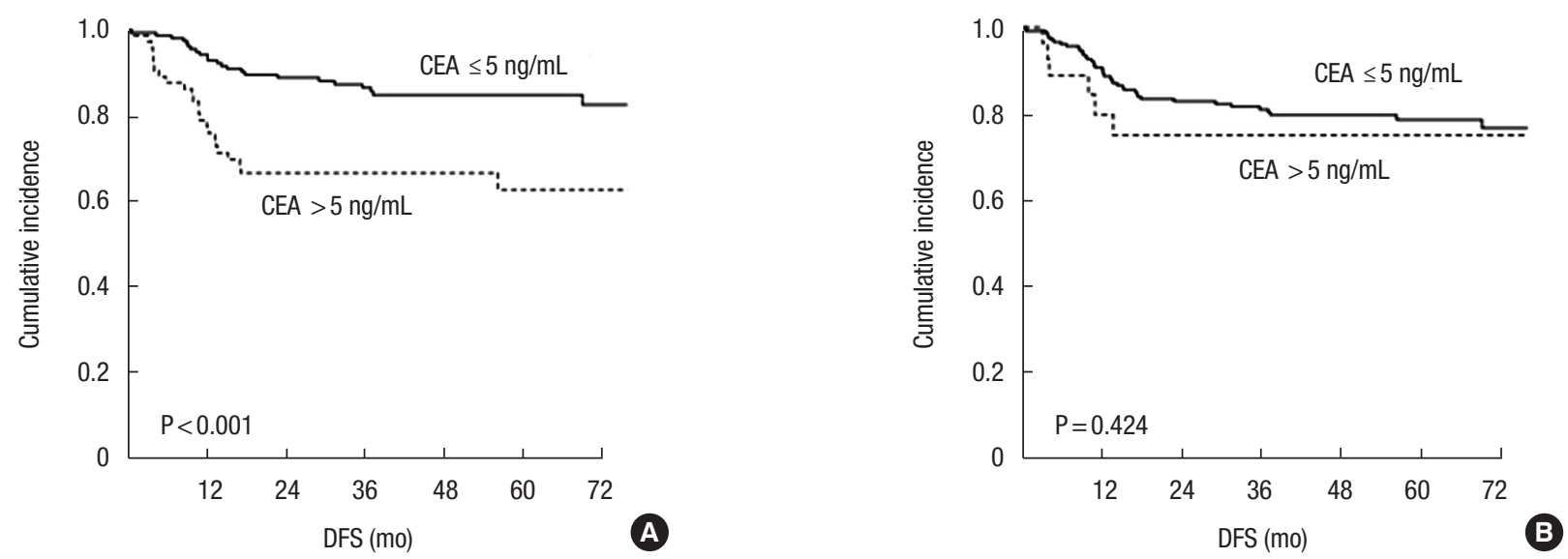

Fig. 2. Disease-free survival (DFS) according to serum carcinoembryonic antigen (CEA) levels (A) before surgery and (B) after surgery. 


\section{Annals of \\ Coloproctology Jung il Joo, et al.}

Prognostic Impact of Carcinoembryonic Antigen Levels in Rectal Cancer Patients Who Had Received

Neoadjuvant Chemoradiotherapy

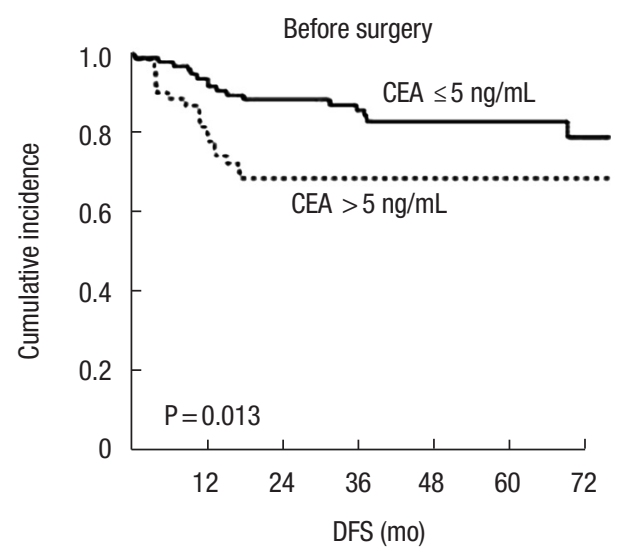

Before surgery

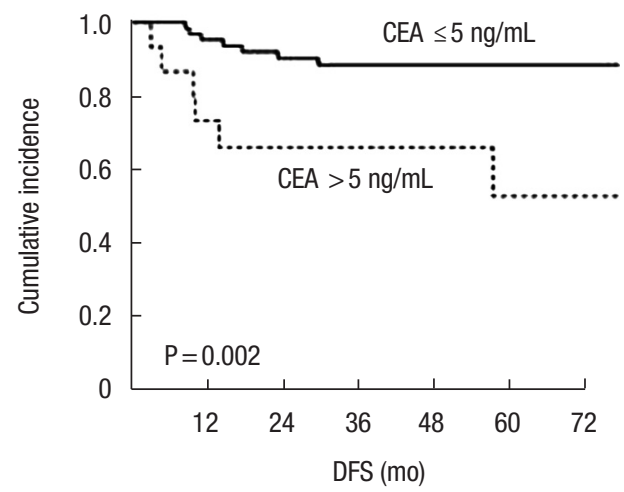

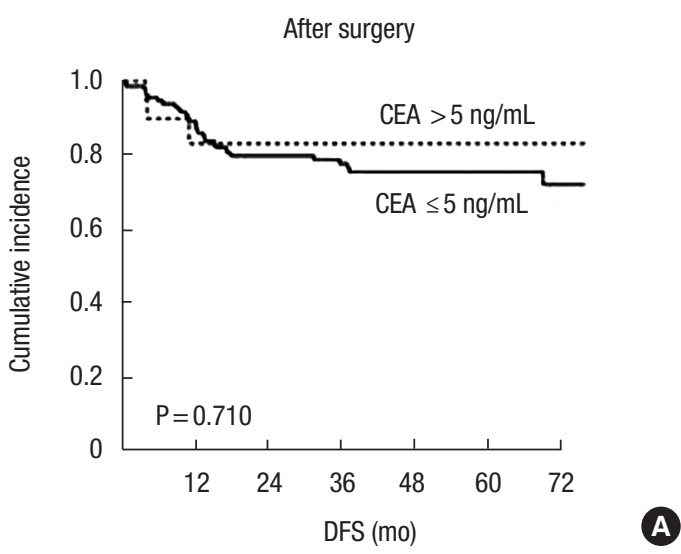

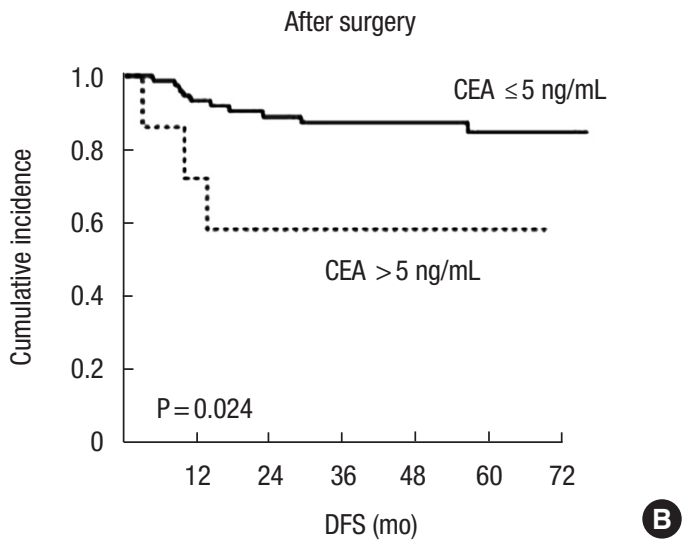

Fig. 3. Disease-free survival (DFS) according to serum carcinoembryonic antigen (CEA) levels before and after surgery in patients who had (A) not received neoadjuvant chemoradiotherapy (nCRT) and (B) received nCRT.

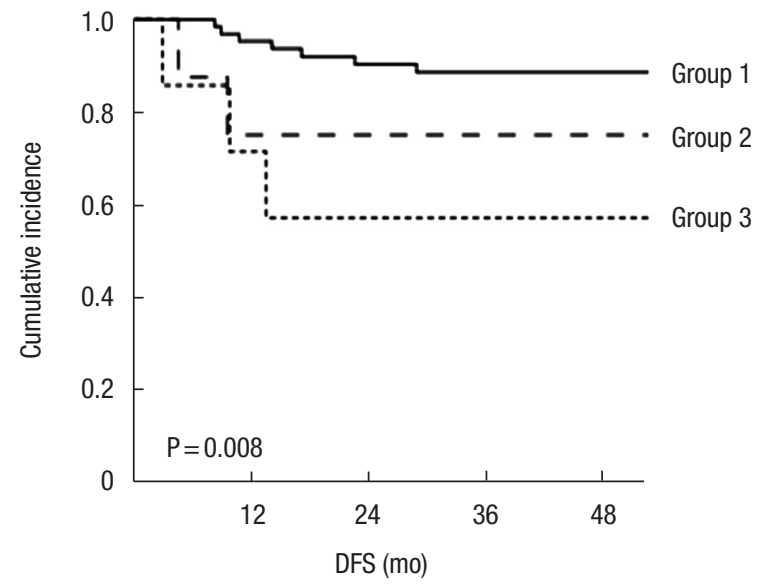

Fig. 4. Disease-free survival (DFS) according to changes in carcinoembryonic antigen (CEA) levels in patients who had received neoadjuvant chemoradiotherapy. CEA level $(\mathrm{ng} / \mathrm{mL})$ : group 1, preoperative $\leq 5$ and postoperative $\leq 5$; group 2 , preoperative $>5$ and postoperative $\leq 5$; and group 3 , preoperative $>5$ and postoperative $>5$.

\section{DISCUSSION}

In this study, we investigated the prognostic value of CEA levels according to $\mathrm{nCRT}$ in rectal cancer patients who underwent radical surgery. We observed that preoperative CEA level was a prognostic factor regardless of nCRT, and postoperative CEA level was a significant prognostic factor only in patients receiving nCRT. In patients who had received nCRT, patients with continuing CEA level elevation after surgery showed significantly worse DFS compared to patients with lower CEA level postoperatively.

Many oncologic researchers have investigated the role of serum CEA as a prognostic indicator in CRC [13-18]. In locally advanced rectal cancer, the standard treatment is nCRT followed by radical surgery, and the relationship of CEA and response to nCRT has been studied [6,7]. Some studies have reported that patients with elevated serum CEA levels before and after nCRT or surgery showed poor oncologic outcomes [19-22], whereas other studies have reported no relationship between serum CEA and oncologic outcomes $[23,24]$. Thus, the association between serum CEA level and nCRT in rectal cancer is controversial.

CEA is a glycoprotein expressed on colonic epithelial cells and 
Table 2. Prognostic factors for disease-free survival

\begin{tabular}{|c|c|c|c|c|c|c|}
\hline \multirow{3}{*}{ Variable } & \multicolumn{3}{|c|}{ nCRT (-) } & \multicolumn{3}{|c|}{ nCRT (+) } \\
\hline & \multirow{2}{*}{$\begin{array}{c}\text { Univariate } \\
\text { P-value }\end{array}$} & \multicolumn{2}{|c|}{ Multivariate } & \multirow{2}{*}{$\begin{array}{c}\text { Univariate } \\
\text { P-value } \\
\end{array}$} & \multicolumn{2}{|c|}{ Multivariate } \\
\hline & & $\mathrm{HR}(95 \% \mathrm{Cl})$ & P-value & & $\mathrm{HR}(95 \% \mathrm{Cl})$ & P-value \\
\hline Preoperative CEA (ng/mL), $>5$ vs. $\leq 5$ & 0.016 & $2.017(1.002-4.058)$ & 0.049 & 0.005 & $5.443(1.356-21.848)$ & 0.017 \\
\hline Postoperative CEA (ng/mL), $>5$ vs. $\leq 5$ & 0.711 & & & 0.013 & $3.983(1.093-14.515)$ & 0.036 \\
\hline Age (yr), $\geq 65$ vs. $<65$ & 0.209 & & & 0.975 & & \\
\hline Sex, female vs. male & 0.707 & & & 0.705 & & \\
\hline Cancer obstruction, yes vs. no & 0.866 & & & 0.114 & & \\
\hline Cancer perforation, yes vs. no & 0.542 & & & 0.793 & & \\
\hline p(or yp)Stage & 0.008 & & 0.030 & 0.036 & & 0.137 \\
\hline II vs. 0-I & & $2.978(0.848-10.453)$ & 0.089 & & $6.697(0.823-54.479)$ & 0.075 \\
\hline III vs. 0-I & & $4.557(1.573-13.201)$ & 0.005 & & $8.845(1.032-75.778)$ & 0.047 \\
\hline Cell type, PD/MUC/SRC vs. WD/MD & 0.626 & & & 0.031 & $3.599(0.864-14.996)$ & 0.079 \\
\hline Lymphatic invasion, yes vs. no & 0.505 & & & 0.338 & & \\
\hline Vascular invasion, yes vs. no & 0.050 & $1.644(0.771-3.503)$ & 0.198 & 0.119 & & \\
\hline Perineural invasion, yes vs. no & 0.599 & & & 0.733 & & \\
\hline Adjuvant treatment, yes vs. no & 0.016 & $0.601(0.538-2.922)$ & 0.971 & 0.236 & & \\
\hline
\end{tabular}

$\mathrm{nCRT}$, neoadjuvant chemoradiotherapy; HR, hazard ratio; $\mathrm{Cl}$, confidence interval; CEA, carcinoembryonic antigen; $\mathrm{p}$ (or yp)Stage, pathologic stage after surgical resection in patients who received preoperative treatment; PD, poorly differentiated; MUC, mucinous carcinoma; SRC, signet ring cell carcinoma; WD, well differentiated; MD, moderately differentiated.

secreted into the bloodstream, leading to an increase in serum level [25]. CEA is reliable for detecting recurrence and is used to evaluate the biological activity of malignancies. Thus, it is recommended by the American Society of Clinical Oncology and the European Society for Medical Oncology as a prognostic biomarker during routine follow-up for CRC after surgical resection $[5,11]$. In this study, CEA was an independent prognostic factor both preoperatively and postoperatively in patients who had received nCRT. Patients with persistent postoperative CEA level elevation showed the worst DFS. There may be tumor cells that have escaped systemic control while local control of tumor cells by nCRT. CEA reflects the burden of these circulating tumor cells and has been used as a marker for detecting micrometastases [26-30]. Our findings may be due to persistence of micrometastases during nCRT and continued production of CEA as a result. On the other hand, most of patients in non-nCRT group are clinically early staged rectal cancer compared to those in nCRT group. In non-nCRT group, the elevated CEA level after surgery is may be due to false positive. This finding has also been revealed in several existing literature [30-33]. Our results may be useful in predicting recurrence and establishing treatment strategies in rectal cancer patients who received nCRT, especially in patients with continuing CEA level elevation after surgery.

There were some limitations in our study. This study was performed retrospectively in a single institution. There was a lack of consideration of other factors contributing to false-positive CEA elevation. We have no data on CEA level prior to surgery after nCRT. Also, we did not analyze the association between CEA level and tumor response to nCRT.

In conclusion, serum CEA level was an independent prognostic factor both preoperatively and postoperatively in rectal cancer patients who had received nCRT. Close observation and intensive treatment are needed in patients with persistent CEA level elevation after surgery.

\section{CONFLICTS OF INTEREST}

No potential conflict of interest relevant to this article was reported.

\section{SUPPLEMENTARY MATERIALS}

Supplementary materials for this study are presented online (available at https://doi.org/10.3393/ac.2020.11.27).

\section{REFERENCES}

1. Oh BY, Lee WY, Jung S, Hong HK, Nam DH, Park YA, et al. Correlation between tumor engraftment in patient-derived xenograft models and clinical outcomes in colorectal cancer patients. Oncotarget 2015;6:16059-68.

2. Jemal A, Bray F, Center MM, Ferlay J, Ward E, Forman D. Global cancer statistics. CA Cancer J Clin 2011;61:69-90. 
3. Yang Y, Huang X, Sun J, Gao P, Song Y, Chen X, et al. Prognostic value of perineural invasion in colorectal cancer: a meta-analysis. J Gastrointest Surg 2015;19:1113-22.

4. Dienstmann R, Salazar R, Tabernero J. Personalizing colon cancer adjuvant therapy: selecting optimal treatments for individual patients. J Clin Oncol 2015;33:1787-96.

5. Duffy MJ, Lamerz R, Haglund C, Nicolini A, Kalousová M, Holubec L, et al. Tumor markers in colorectal cancer, gastric cancer and gastrointestinal stromal cancers: European group on tumor markers 2014 guidelines update. Int J Cancer 2014;134:2513-22.

6. Ryan JE, Warrier SK, Lynch AC, Ramsay RG, Phillips WA, Heriot AG. Predicting pathological complete response to neoadjuvant chemoradiotherapy in locally advanced rectal cancer: a systematic review. Colorectal Dis 2016;18:234-46.

7. Kim NK, Hur H. New perspectives on predictive biomarkers of tumor response and their clinical application in preoperative chemoradiation therapy for rectal cancer. Yonsei Med J 2015;56:146177.

8. Molinari C, Matteucci F, Caroli P, Passardi A. Biomarkers and molecular imaging as predictors of response to neoadjuvant chemoradiotherapy in patients with locally advanced rectal cancer. Clin Colorectal Cancer 2015;14:227-38.

9. Lim SH, Chua W, Henderson C, Ng W, Shin JS, Chantrill L, et al. Predictive and prognostic biomarkers for neoadjuvant chemoradiotherapy in locally advanced rectal cancer. Crit Rev Oncol Hematol 2015;96:67-80.

10. Stiksma J, Grootendorst DC, van der Linden PW. CA 19-9 as a marker in addition to CEA to monitor colorectal cancer. Clin Colorectal Cancer 2014;13:239-44.

11. Locker GY, Hamilton S, Harris J, Jessup JM, Kemeny N, Macdonald JS, et al. ASCO 2006 update of recommendations for the use of tumor markers in gastrointestinal cancer. J Clin Oncol 2006; 24:5313-27.

12. Wanebo HJ, Rao B, Pinsky CM, Hoffman RG, Stearns M, Schwartz $\mathrm{MK}$, et al. Preoperative carcinoembryonic antigen level as a prognostic indicator in colorectal cancer. N Engl J Med 1978;299:44851.

13. Harrison LE, Guillem JG, Paty P, Cohen AM. Preoperative carcinoembryonic antigen predicts outcomes in node-negative colon cancer patients: a multivariate analysis of 572 patients. J Am Coll Surg 1997;185:55-9.

14. Bernardes MV, Feitosa MR, Peria FM, Tirapelli DP, Rocha JJ, Feres O. Comparative evaluation of oncologic outcomes in colon cancer. Acta Cir Bras 2016;31 Suppl 1:34-9.

15. Kirat HT, Ozturk E, Lavery IC, Kiran RP. The predictive value of preoperative carcinoembryonic antigen level in the prognosis of colon cancer. Am J Surg 2012;204:447-52.

16. Moertel CG, O'Fallon JR, Go VL, O'Connell MJ, Thynne GS. The preoperative carcinoembryonic antigen test in the diagnosis, staging, and prognosis of colorectal cancer. Cancer 1986;58:603-10.

17. Slentz K, Senagore A, Hibbert J, Mazier WP, Talbott TM. Can preoperative and postoperative CEA predict survival after colon cancer resection? Am Surg 1994;60:528-32.

18. Wolmark N, Fisher B, Wieand HS, Henry RS, Lerner H, LegaultPoisson S, et al. The prognostic significance of preoperative carcinoembryonic antigen levels in colorectal cancer: results from NSABP (National Surgical Adjuvant Breast and Bowel Project) clinical trials. Ann Surg 1984;199:375-82.

19. Yang KL, Yang SH, Liang WY, Kuo YJ, Lin JK, Lin TC, et al. Carcinoembryonic antigen (CEA) level, CEA ratio, and treatment outcome of rectal cancer patients receiving pre-operative chemoradiation and surgery. Radiat Oncol 2013;8:43.

20. Park JW, Lim SB, Kim DY, Jung KH, Hong YS, Chang HJ, et al. Carcinoembryonic antigen as a predictor of pathologic response and a prognostic factor in locally advanced rectal cancer patients treated with preoperative chemoradiotherapy and surgery. Int J Radiat Oncol Biol Phys 2009;74:810-7.

21. Jang NY, Kang SB, Kim DW, Kim JH, Lee KW, Kim IA, et al. The role of carcinoembryonic antigen after neoadjuvant chemoradiotherapy in patients with rectal cancer. Dis Colon Rectum 2011;54: 245-52.

22. Chung MJ, Chung SM, Kim JY, Ryu MR. Prognostic significance of serum carcinoembryonic antigen normalization on survival in rectal cancer treated with preoperative chemoradiation. Cancer Res Treat 2013;45:186-92.

23. Perez RO, São Julião GP, Habr-Gama A, Kiss D, Proscurshim I, Campos FG, et al. The role of carcinoembriogenic antigen in predicting response and survival to neoadjuvant chemoradiotherapy for distal rectal cancer. Dis Colon Rectum 2009;52:1137-43.

24. Garland ML, Vather R, Bunkley N, Pearse M, Bissett IP. Clinical tumour size and nodal status predict pathologic complete response following neoadjuvant chemoradiotherapy for rectal cancer. Int J Colorectal Dis 2014;29:301-7.

25. Göksu SS, Göksu UA, Gündüz S, Coskun HS. Rising CEA levels in a patient with colon carcinoma: metachronous medullary thyroid cancer. Int J Biol Markers 2014;29:e184-6.

26. Ho SB, Hyslop A, Albrecht R, Jacobson A, Spencer M, Rothenberger DA, et al. Quantification of colorectal cancer micrometastases in lymph nodes by nested and real-time reverse transcriptase-PCR analysis for carcinoembryonic antigen. Clin Cancer Res 2004;10:5777-84.

27. Noura S, Yamamoto H, Ohnishi T, Masuda N, Matsumoto T, Takayama $\mathrm{O}$, et al. Comparative detection of lymph node micrometastases of stage II colorectal cancer by reverse transcriptase polymerase chain reaction and immunohistochemistry. J Clin Oncol 2002;20:4232-41.

28. Hekman MC, Rijpkema M, Bos DL, Oosterwijk E, Goldenberg DM, Mulders PF, et al. Detection of micrometastases using SPECT/ fluorescence dual-modality imaging in a CEA-expressing tumor model. J Nucl Med 2017;58:706-10.

29. Murono K, Kazama S, Yamaguchi H, Kawai K, Ishihara S, Sunami $\mathrm{E}$, et al. Detection of carcinoembryonic antigen $\mathrm{mRNA}$ in peritoneal lavage by the transcription-reverse transcription concerted method indicates poor prognosis in patients with stage II and III 
colon cancer. Surgery 2015;157:322-30.

30. Saito G, Sadahiro S, Ogimi T, Miyakita H, Okada K, Tanaka A, et al. Relations of changes in serum carcinoembryonic antigen levels before and after neoadjuvant chemoradiotherapy and after surgery to histologic response and outcomes in patients with locally advanced rectal cancer. Oncology 2018;94:167-75.

31. Hara M, Sato M, Takahashi H, Takayama S, Takeyama H. Does serum carcinoembryonic antigen elevation in patients with postoperative stage II colorectal cancer indicate recurrence?: comparison with stage III. J Surg Oncol 2010;102:154-7.
32. Nakamura Y, Shida D, Tanabe T, Takamizawa Y, Imaizumi J, Ahiko Y, et al. Prognostic impact of preoperatively elevated and postoperatively normalized carcinoembryonic antigen levels following curative resection of stage I-III rectal cancer. Cancer Med 2020; 9:653-62.

33. Konishi T, Shimada Y, Hsu M, Tufts L, Jimenez-Rodriguez R, Cercek A, et al. Association of preoperative and postoperative serum carcinoembryonic antigen and colon cancer outcome. JAMA Oncol 2018;4:309-15. 